\title{
The Construction Path of University Smart Libraries Facing Strategic Emerging Industries
}

\author{
Xiao nan $\operatorname{nan}^{1}, *$ \\ ${ }^{1}$ Jianghan University Library, Wuhan HuBei 430056, China
}

\begin{abstract}
The development of strategic emerging industries is inseparable from the support and guarantee of information resources. The multiplier effect of information resources can enhance the industry's independent innovation and international competitiveness. Under the background of the all-round development of strategic emerging industries and the acceleration of the construction of emerging professional disciplines in universities, the intelligent construction of university libraries is an inevitable choice. This article aims to analyze the necessity of intelligent construction of academic libraries for strategic emerging industries, build a new system model of intelligent intelligent libraries in universities, propose cultivating intelligent groups to improve intelligent literacy, and use intelligent technology to tap new kinetic energy of university libraries. Strengthen the construction path of new ways of space management innovation and development of smart cities.
\end{abstract}

\section{Introduction}

Strategic emerging industries are based on major technological breakthroughs and major development needs, and play a major leading role in the overall economic and social and long-term development. They are knowledge-intensive, low-consumption of material resources, large growth potential, and good overall benefits. The "14th Five-Year Plan" period is a critical period for the development of China's strategic emerging industries. China will accelerate the technological innovation and application of industrial Internet, big data, artificial intelligence, advanced communications, integrated circuits, and ultra-high-definition displays, and comprehensively improve the information technology The core competitiveness of the industry. Strategic emerging industries must seize the multiplier effect of new production factors such as information technology and data resources, and create new value-added space in all aspects of production, circulation, and consumption. Thanks to the continuous application of Internet information technology, intelligence has become a new development concept and model in the library field. In the "Statement on Libraries and Artificial Intelligence" issued by IFLA in September 2020, it was mentioned that artificial intelligence is reshaping the business model of libraries, and that libraries are encouraged to participate in cultivating users' data literacy. Libraries should also become The leader in the information data chain [1]. University libraries not only play an important role in the teaching and scientific research of the school, but also in the school-enterprise cooperation and direct service to social enterprises. Some academic libraries in China have launched information services for the society and enterprises and achieved positive results [2]. As strategic emerging industries led by cutting-edge technologies such as big data, quantum computing, and new materials are becoming new drivers of economic growth, academic libraries should seize the opportunity to use their own advantages to serve the development of strategic emerging industries. To realize this kind of functional transformation and service transformation, university libraries must accelerate their pace of intelligent construction. University smart library is not only a new development form of library that adapts to technological changes, but also a new development concept for future school education, subject construction and the needs of new industries in society.

\section{Types and characteristics of information resource demand in strategic emerging industries}

The types of information needs of strategic emerging industries mainly include business information, scientific and technological information, and policy information. (1) Commercial information. The content of business information includes market information and competitive intelligence. This type of information has a direct effect on the development of enterprises and is therefore the focus of strategic emerging industrial enterprises. (2) Scientific and technological information. Scientific and technological information refers to the scientific knowledge and academic information required by strategic emerging industrial enterprises in the process of product development, including scientific and

\footnotetext{
*Xiao nan nan :447548938@qq.com
} 
technological papers, conference documents, scientific and technological books, patent information, standard information, etc. (3) Policy information. Policy information is information released by government departments, which are all publicly available information, which can be subdivided into types such as industrial policies, corporate incentive policies, and industry management policies.

Demand characteristics.First, high quality. The information required by strategic emerging industries is of high quality, which is mainly reflected in the novelty, accuracy and timeliness of information. Therefore, the provision of information services must be accurate, timely, convenient and fast to reduce corporate risks. Second, diversity. The types of information required by strategic emerging industries are diverse, involving different stages and the entire process such as product development, achievement transformation, production, sales, installation, and after-sales service.

\section{The necessity of the intelligent transformation of academic libraries in strategic emerging industries}

The development of informatization has entered a new stage, and the level of intelligence in technology applications has continued to increase. Information technology has become the core engine leading the economic development of emerging industries. Facing the diverse needs of information resources in strategic emerging industries, the transformation of intellectualization of university libraries is also imminent.

\subsection{Meet the needs of the coordinated development of universities and strategic emerging industries}

The rapid development of strategic emerging industries puts forward higher requirements for university professional construction, discipline development, talent training, collaborative innovation of industry, university and research, and the transformation of university scientific research results. In 2010, the Ministry of Education added 140 undergraduate majors related to strategic emerging industries. In 2019, the Ministry of Education announced the first batch of 8 strategic emerging industries-related undergraduate majors, including new energy science and engineering, nanomaterials and technology, and new energy materials. And devices, microelectronics science and engineering, functional materials, smart grid information engineering, Internet of Things engineering, biopharmaceuticals, etc. University libraries must adapt to the new requirements of their service functions and content in the construction of emerging majors in universities, and through intelligent construction, closely follow the development trend of strategic emerging industries and realize the docking of functions and services.

\subsection{The need for resource service methods of university libraries}

On the one hand, as the Internet further extends to the Internet of Things, the real-time status of more and more physical entities is widely collected, transmitted, and aggregated, becoming an important data foundation for strategic emerging industries. The various physical carrier literature information collected by the library also needs to be associated with each other, with users, with the physical resources of other libraries, and even with other intelligent facilities and equipment. On the other hand, while the resources accumulated in human social information activities continue to increase exponentially, network data resources are increasingly showing a situation of structured and unstructured coexistence and large-scale exchange, sharing and aggregation through the network, a strategic emerging industry Various fields of the company have put forward higher and higher requirements for big data mining and intelligent analysis. The transmission rate of next-generation information networks continues to increase, and strategic emerging industries place higher demands on the agility of various types of knowledge and information services.

\subsection{The need for college libraries to create smart spaces}

With the popularization and application of various intelligent technologies in various fields of economic and social life, people are becoming more and more accustomed to and accustomed to intelligent scenarios in daily life, study, and work. The demand for intelligent knowledge service experience has become increasingly prominent. Driven by both technology and demand, the library is bound to usher in new ideas and new trends in building space renovation. Facing the historical opportunities and challenges brought by the development of a smart society, domestic academic libraries took the lead in actively exploring the areas of smart space planning, smart venue construction, smart business management, and smart service innovation. Positive progress has been made in the application of artificial intelligence technology in areas such as face recognition, non-sense lending, robot navigation, virtual explanation, and simulation experience, which has effectively improved the efficiency of business management and the user's online and offline learning and reading experience. The intelligent inventory robot developed by Nanjing University Library, relying on RFID perception, computer vision and other intelligent technologies, can realize accurate and reliable automatic book inventory. The book inventory efficiency exceeds 20,000 books per hour, and the missed reading rate is less than $1 \%[4]$.

\subsection{University libraries use smart technology to achieve high-quality development needs}

In an era when new-generation technologies such as big data, artificial intelligence, and the Internet of Things are widely used, it has become the consensus of academia and 
industry to accelerate the construction of smart libraries and smart services with "data-driven" as the core. University libraries should "steadily and steadily", take the express train of smart technology, and lead the new form of smart libraries. From the academic perspective, the current library and information subject is in the background of "numerical intelligence". At the same time, the "numerical intelligence" environment has changed to a certain extent the problem domain and resource concept in the field of image and information, and has given the subject more practical power. , And expanded the scope of influence of the subject of graphic information [5]. At the same time, the industry is constantly beginning to practice "data-driven" solutions. University libraries should take the express train of smart technology to lead the new form of smart libraries.

\section{The model of building a new smart system of academic libraries for strategic emerging industries}

Smart service refers to user-oriented intelligence in all aspects of the entire process from resource collection to use and decision-making. Therefore, the smart service platform includes a resource selection platform, a resource-integrated central knowledge base, a service platform that provides smart services, and a decisionmaking platform for readers to use resources. In general, optimizing user services has always been the original intention of the library's reform. At the same time, it is supplemented by an open ecological environment and an integrated management model of paper, electricity and data. These together constitute the core of a new generation of library smart service platforms.

The first step in the construction of smart services is the infrastructure construction supported by technology. Big data is the most important "digital gold mine" in the new era. The "big data" of the library is mainly the library's own bibliographic data, electronic resource data, academic-related data, user perception data, buildingrelated data, space-related data, decision-related data, etc. The second step in the construction of smart services is a data-driven full terminal service. In addition to its own paper resources, electronic resources and digital assets, the library also has behavioral data operated by personnel. These data are collected and processed by the library to form data sets with their own attributes. After standardized processing, different data sets are presented in the form of report engine, recommendation engine, etc., to realize data management applications and service transformation.

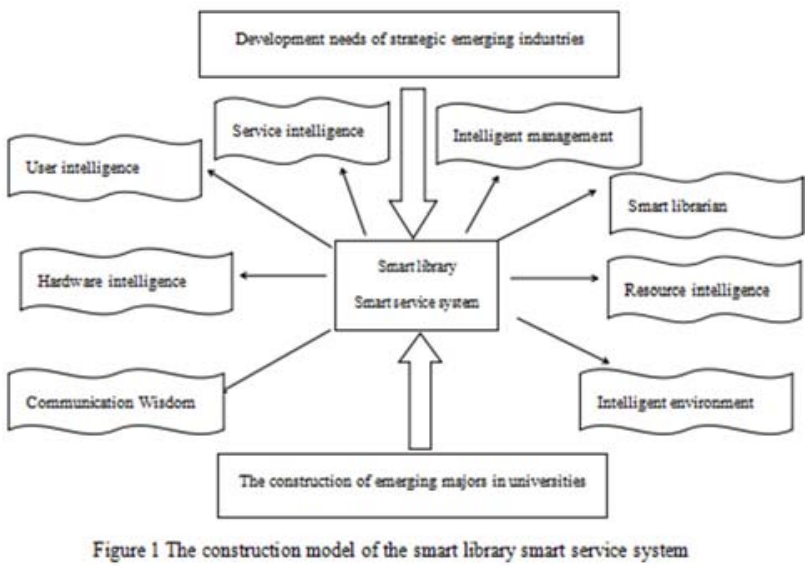

The new generation of library intelligent service platform should be characterized by "integration" and "convergence", and establish a new service system architecture. It can be based on readers' decision-making procurement platform, adopt the integrated management model of paper, digital and electricity, and support new associations. Data and metadata description standards, and system cloud deployment is adopted to gradually integrate with resource providers such as database vendors and booksellers to achieve high integration of multiple composite resource management systems. The smart library smart service system includes 8 modules: environment smart, hardware smart, resource smart, communication smart, user smart, librarian smart, service smart, and management smart. Through module construction, it can respond to emerging universities. Professional construction requirements and development needs of strategic emerging industries. Figure 1

\section{Development path of smart libraries in local universities}

\subsection{Cultivate smart groups and improve smart literacy}

The intelligentization of professional librarians is one of the core contents of smart library services. Intelligent professional librarians use the "big data" in intelligence activities to order, transform and realize professionalization through intelligent technology. Really play its fundamental role in the construction of emerging disciplines and services for emerging industries. The key to the development of smart libraries lies in people and professional librarians. In fact, it is to cultivate professional librarians into real smart librarians. Smart librarians in colleges and universities should focus on the cultivation of four core literacy, including professional literacy, information literacy, reading literacy, and information literacy. Through the formation of intellectual literacy, librarians are actively transforming into professional librarians, subject librarians, and intelligence experts. Through the talent cultivation mechanism of smart librarians, college libraries form a smart library based on the library's smart platform to organize, integrate and reconstruct knowledge and business processes in this 
field, realize innovations, serve researchers at different levels, and become a smart library with professional characteristics The team of members has become the core competitiveness of the realization of smart library functions [5]. Professional librarians should actively use information technology such as artificial intelligence and $5 \mathrm{G}$, focus on subject intelligence services, gain insights into the information fog, and actively carry out information precision poverty alleviation services, fixed topic services, scientific and technological novelty search, patent applications, ESI discipline development analysis, and digital Humanities research and other services.

The core concept of a smart library is smart service. The ultimate realization of smart service requires the participation of smart users and readers in addition to smart librarians. With the application and popularization of information technology such as artificial intelligence and $5 \mathrm{G}$, the data literacy, knowledge literacy, and intelligence literacy of library users will become a strong support for the realization of smart library functions. In adapting to the coordinated development of universities and strategic emerging industries, smart libraries jointly promote the smart knowledge literacy, smart ability literacy, and smart cultural literacy of user groups, which is conducive to promoting the service functions of smart libraries and is also conducive to the innovation of smart venues.

\subsection{Use intelligent technology to tap new kinetic energy of university libraries}

At present, technical research on smart libraries is mainly concentrated on smart devices and smart systems. Inventory robots and intelligent chat robots are applied and practiced in Nanjing University, Tsinghua University and other universities. With the continuous "joining" of smart devices in the future, the staff of the library's reference department, cataloging department, and circulation department will gradually be replaced by machines, and data collection and management, user navigation and consultation will all be completed by machines. Smart devices have improved the smart devices of library services, so the quality of service needs to be completed through data technology and smart systems. The intelligent system also supports the library to process massive amounts of user data and conduct intelligent and accurate user behavior analysis, so as to tap other values implied by user behavior. The update of smart equipment can not only reduce the basic labor of librarians and improve work accuracy, but more importantly, the embedding of smart technology can explore new ways for libraries, expand new services, tap new kinetic energy, and promote continuous changes in smart libraries.

\subsection{Strengthen space management and innovate new ways of developing smart cities}

First, improve the construction of basic space. The space reengineering of the library is reflected in the transformation of service methods and management methods. The library creates a special independent space based on the emerging disciplines, special collections and cultural heritage of universities, modularized and flexible the library, and customized special service spaces in accordance with the changes in the needs of emerging enterprises.

Second, strengthen the construction of the middlelevel intelligent space system. The space management system of a university library first needs to establish a space database, which is mainly used to store the location information of various areas and facilities of the library to help users accurately locate. A complete system system is the key to the construction of the middle-level intelligent space system.

Third, speed up the construction of top-level artificial intelligence data. The top-level smart space utilizes the massive user behavior and habits data that has been built in the middle and lower levels to form an artificial intelligence data center to realize the "super-convergence" of the smart space. Through the micro-service architecture, the interactive system in the space is designed with a unified top-level architecture, unified management and control, unified analysis and storage, data collection and summary from different dimensions, and the intelligent space unified platform is integrated through the interface layer of the system. Use high-tech technology to analyze and statistics readers' spatial data, provide one-to-one intelligent push of resources and services, intelligent interaction, etc., to "build files" for each enterprise user, update in real time, and form a privacy data protection mechanism to continuously deepen and improve books Library service efficiency.

\section{Conclusion}

As an important base for schools and socialized information services, university libraries have collection resources and professional talents that other information service organizations cannot match, and they have the advantages of providing information services for strategic emerging industries. Under the premise of fulfilling the main function of serving the teaching and scientific research of teachers and students of the university, the smart library of colleges and universities expands the service objects and scope, and provides information services for strategic emerging industries. It also has positive practical significance. The first is to serve the enterprise and expand the industry; the second is to enhance its own intelligence capabilities and better serve professional development.

\section{References}

1. IFLA.IFLA statement on libraries and artificial intelligence[EB/OL].[2020-10-05].https:/ /www.Ifla.org /publications/node / 93397.

2. Sun An. Research on the Strategies of University Libraries to Carry out Information Services for Regional Enterprises[J]. Library Development, 2013(2): 51-55 
3. Duan Meizhen, Feng Zhanying, Li Wen, et al. Research on the development trend and path of libraries during the "14th Five-Year Plan" period[J]. Chinese Journal of Medical Library and Information, 2021, 30(1): 5-11.

4. Fan Huili, Shao Bo. Innovative Practice and Thinking on Book Inventory of Intelligent Robots-Taking Nanjing University Library as an Example[J].Library, 2018.09

5. Sun Jianjun, Li Yang, Pei Lei. Thoughts on the Transformation of Library and Information Files in the Empowering Era of "Digital Intelligence"[J]. Library, Information, and Knowledge, 2020( 3): 2227. 